\title{
EFEITO DO ESTÁDIO DE DESENVOLVIMENTO DO FRUTO SOBRE A QUALIDADE DA SEMENTE DO CULTIVAR PATRÍCIA DE VIDEIRA (1)
}

JOCELY ANDREUCCETTI MAEDA, Seção de Sementes, Instituto Agronômico, MARIA DE FATIMA DOMINGOS ALEIXO PEREIRA, Departamento de Fisiologia Vegetal, Universidade Estadual de Campinas, e MAURILO MONTEIRO TERRA, Seçäo de Viticultura, Instituto Agronômico.

\section{RESUMO}

Durante a maturação do fruto do cultivar Patricia de videira, podem-se identificar três diferentes estádios de desenvolvimento, com base, principalmente, na coloração do fruto. Neste trabalho, coletaram-se sementes de cada estádio, armazenando-as por diferentes períodos, sendo a qualidade examinada após a colheita e no armazenamento, visando detectar o ponto de menor índice de dormência e máxima germinação. O estádio de maturação do fruto afetou-lhes a viabilidade: as sementes dos frutos maduros sempre apresentaram os maiores valores de viabilidade, ao contrário daquelas de frutos imaturos. Durante o armazenamento, houve diminuição da viabilidade nos três tipos de sementes testados, sendo as de frutos imaturos as mais afetadas. Em sementes de frutos maduros, ocorreu redução da dormência durante o armazenamento. Antes e depois do armazenamento, as sementes dos frutos maduros e meio maduros emergiram mais rápido e houve desenvolvimento de maior número de plântulas, com maior peso de matéria seca, comparativamente às sementes do fruto imaturo. A máxima germinação e vigor da semente são alcançados em sua maturidade fisiológica, aspecto esse a ser considerado antes da colheita, para que se obtenham sementes de alta qualidade.

(1) Recebido para publicação a 19 de outubro de 1983 . 


\section{INTRODUCÃO}

A definição de qualidade de sementes pode abranger diferentes aspectos, de acordo com o interesse de quem a define: homogeneidade genética, aparência física, pureza e uniformidade, viabilidade da semente e, muitas vezes, comportamento da planta no campo, em termos de emergência, desenvolvimento da plântula, crescimento e, finalmente, co. lheita (MAGUTRE, 6). De maneira geral, qualidade da semente é o somatório de todos os atributos genéticos, físicos, fisioiógicos e sanitários que a conduzem à germinação e ao desenvolviment’s de uma plântula normal.

A máxima qualidade da semente é atingida por vcasião da sua maturidade fisiológica. A partir desse ponto, inicia-se a deterioração, que pode ser retardada ou mantida numa velocidade mínıma por condicões ideais de colheita, secagem, beneficiamento e armazejamento, numa tentativa de manter a qualidade tão próxima quanto possivel do ponto mais alto que foi atingido. Em sementes de soja, foi notada uma redução na germinação e vigor à medida que a colheita $\mathrm{s}_{\mathfrak{2}}$ distanciou dì maturidade fisiológica, tanto antes como depois desse ponto (AZEVEDO, 2). Em sementes de abóbora, foram observados acréscimos na germinação e vigor das sementes à medida que aumentava a idade dos frutos colhidos (ARAÚJO et alii, 1).

Segundo Boletim da Agricultura (in 5), três fatores influem sobre a maturação das uvas: a variedade da videira, o clima c o tratamento dispensado à cultura. A maturação fisiológica se verifica çuando o pedicelo que suporta a baga se torna colorido e, a película, inteiramente matizada da coloração que lhe é própria, se cobre de uma tênue camada cerosa. Neste momento se estabelece a capacidade de germinação da semente da uva (RIVES, 9). No entanto, nem todos os cachos mudam de coloração ao mesmo tempo; durante a época da maturação, existem cachos totalmente verdes, cachos em fase intermediária, com bagas verdes e bagas escuras, e cachos totalmente escuros. Como para fins de melhoramento são necessárias sementes com o máximo foder germinativo, coletaram-se os frutos nas três fases, determinando-se, então, a qualidade das sementes, e durante o armazenamento, visando ainda detectar a época de mínima ocorrência de dormência, normalmente encontrada nesta espécie de semente.

\section{MATERIAL E MĒTOdOS}

Foram usadas sementes do cultivar Patrícia de videira, um híbrido complexo de Vitis produzido no Instituto Agronômico de Campinas IAC 871-41 (SANTOS NETO, 10), As plantas foram conduzidas no sistema de manjedoura aberta, na Estação Experimental de Jundiaí (SP).

As sementes foram retiradas, espremendo-se as bagas contra peneira, lavadas e deixadas secar sobre pano, na sombra, para retirada do 
excesso de umidade. A seguir, foram tratadas com o fungicida Arasan 75 (Du Pont), com o ingrediente ativo Thiran (5\%) na proporção de 330 gramas do produto na forma comercial por $100 \mathrm{~kg}$ de sementes.

Foram caracterizados três estádios de desenvolvimento em frutos, segundo sua coloração e grau Brix, determinado mediant. refratômetro manual.

As sementes provenientes desses estádios de maturação do fruto foram embaladas em saco de papel e armazenadas a $20^{\circ} \mathrm{C}$, sendo retiradas amostras de cada tratamento aos 0, 6 e 12 meses. Com essas sementes, foram feitos testes em laboratório (germinação) e em casa de vegetação ("stand" final, velocidade de emergência, peso da matéria seca por plântula) em cada época. Avaliou-se também o peso de mil sementes por ocasião do teste inicial, assim como o teor de umidade.

Para verificação da germinação, em quatro repetições de 50 sementes, elas foram colocadas em rolos de papel especial para germinação. Os rolos foram mantidos na posição vertical em germinador que apresenta sistema constante de circulação de água, em temperatura alternada de $20-30^{\circ} \mathrm{C}$, sendo $20^{\circ} \mathrm{C}$ durante 16 horas e $30^{\circ} \mathrm{C}$ durante oito horas. A verificação do número de sementes germinadas foi efetuada a cada sete dias durante 28 dias. A porcentagem de sementes germinadas foi obtida pela soma da porcentagem de plântulas perfeitamente normais, infectadas e anormais. Seria ideal o teste de tetrazólio (DELOUCHE et alii, 4) para a determinação da viabilidade das sementes no final dos experimentos; no entanto, dadas as características do matterial, tais como pequeno tamanho da semente e grande rigidez do tegumento, outro critério teve que ser adotado. Como semente dormente, foi considerada aquela intumescida, que absorveu água, porém não germinou até o último dia do experimento; nesse caso, as sementes eram resistentes à compressão com o dedo. A semente morta, pelo contrário, além de apresentar tegumento escurecido, estourava facilmente, quando comprimida contra a mesa.

Para estudo da emergência, foram utilizadas quatro repetições de 50 sementes, colocadas à mesma profundidade $(12 \mathrm{~mm})$, distanciadas de $6 \mathrm{~cm}$ entre fileiras, $\mathrm{com} 74 \mathrm{~cm}$ de comprimento, em caixas de madeira contendo terra esterilizada com brometo de metila na proporção de $3 \mathrm{~cm}^{3}$ por $40 \mathrm{~kg}$ de terra, mantidas em casa de vegetação. A colocação de cada repetição na caixa seguiu um sorteio geral. A verificação do número de plântulas emergidas foi feita diariamente para determinação da velocidade de emergência, cujo índice foi calculado de acordo com MAGUT$\mathrm{RE}(\boldsymbol{y})$. Os valores de "stand" final foram obtidos com os resultados finais (40 dias após a semeadura), que foram transformados em porcentagem.

Aos 40 dias a partir da semeadura, foi determinado o peso total da matéria seca de plântulas, que foram cortadas ao nível do solo e secas 
em secador com circulaçāo de ar a $45^{\circ} \mathrm{C}$, até obtençāo de peso constante, o que ocorreu após 24 horas.

Para determinação do peso de mil sementes, foram contadas oito amostras ou repetições de cem sementes, as quais foran pesadas, calculando-se a variância, o desvio-padrão e o coeficiente de variação desses valores. Quando o coeficiente de variação não excedeu 4, o resultado da determinação foi calculado multiplicando-se o peso médio de cenı sementes por 10 , mas quando ultrapassou aquele valor, outras oito repeticões foram avaliadas (BRASIL, 3).

O teor de umidade foi determinado em duas amostras de 50 gramas de sementes.

\section{RESULTADOS E DISCUSSão}

A medida que a colheita do fruto se aproximou do fonto de maturação, aumentou a concentração de açúcares totais, medida no suco do fruto, mostrada pelos valores do grau Brix (Quadro 1).

As sementes provenientes de frutos maduros foram significativamente mais pesadas que as de frutos meio maduros, e estas mais do que aquelas de frutos imaturos. Quanto ao teor de umidade, as diferenças não foram significativas.

QUADRO 1. Coloração e grau Brix dos frutos e peso e teor de umidade das sementes quando provenientes de diferentes estádios de maturação dos frutos

\begin{tabular}{|c|c|c|c|c|}
\hline $\begin{array}{l}\text { Estádio de desenvol- } \\
\text { vimento do fruto }\end{array}$ & $\begin{array}{l}\text { Cor do } \\
\text { fruto }\end{array}$ & $\begin{array}{l}\text { Grau } \\
\text { Brix }\end{array}$ & $\begin{array}{c}\text { Peso de } \\
\text { mil sementes }\end{array}$ & $\begin{array}{l}\text { Teor de } \\
\text { umidade }\end{array}$ \\
\hline & & $\%$ & $\mathrm{~g}$ & $\%$ \\
\hline Imaturo & Verde & 7,5 & 41,8 & 11,8 \\
\hline Meio maduro & Manchado & 13,0 & 51,1 & 11,4 \\
\hline Maduro & Tinta 1 & 16,5 & 53,2 & 11,9 \\
\hline D.M.S. (Tukey $5 \%$ ) & $\longrightarrow$ & - & 0,16 & n.s. \\
\hline
\end{tabular}

(1) Caracteristica do cultivar, quando maduro.

Antes do armazenamento, não houve diferença na germinação das sementes de frutos nos três estádios de desenvolvimentó. Durante o armazenamento, as sementes tanto do fruto imaturo como do meio maduro não diferiram entre si; as sementes do fruto maduro mostraram melhor germinação, sendo a de sementes armazenadas por 12 meses significativamente superior à de sementes não armazenadas (Quadro 2). 


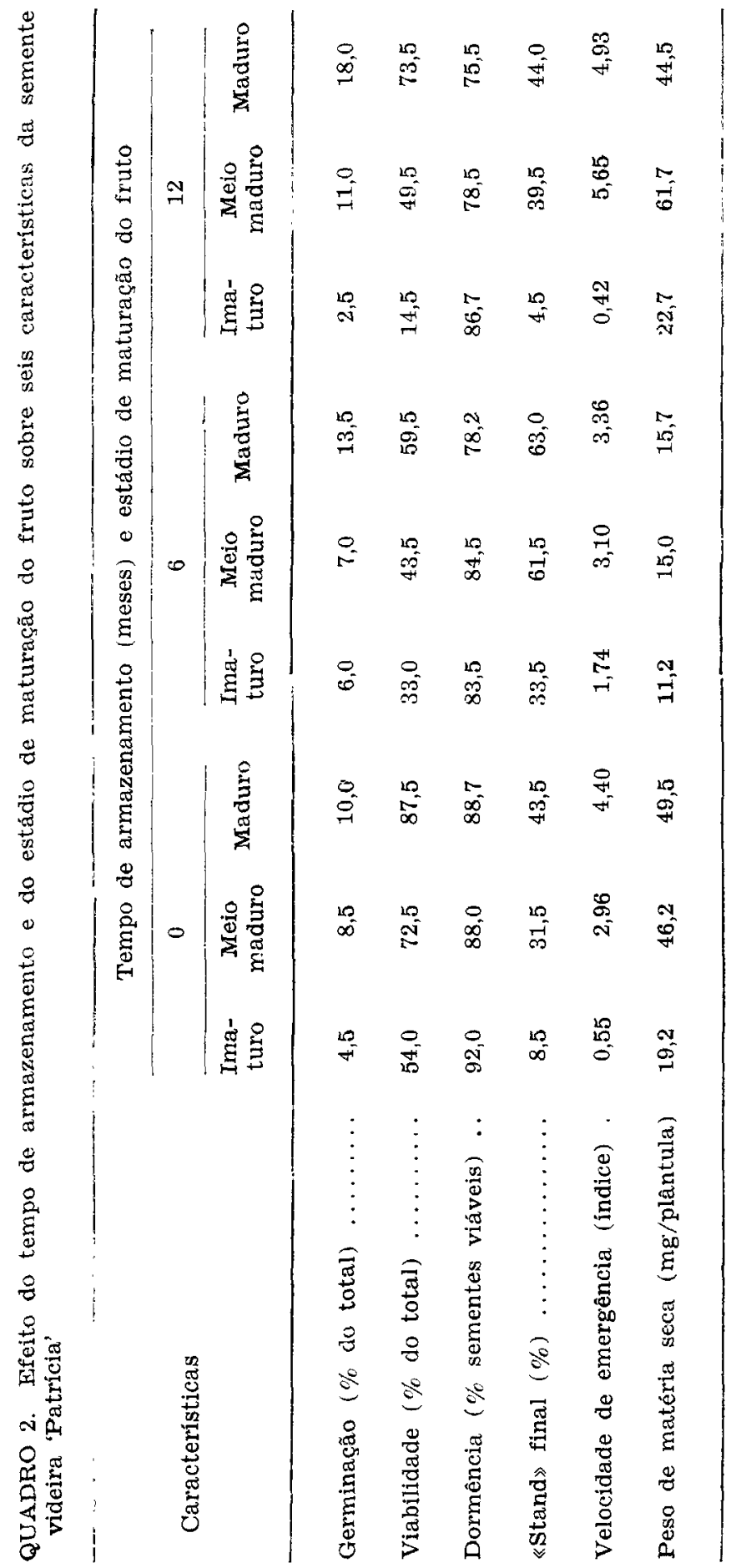

Bragantia, Campinas, 43(2) :659-666, 1984 
Uma vez que as porcentagens de germinação foram muito baixas (cerca de 20\%), procedeu-se ao estudo da viabilidade dessas sementes: tanto o armazenamento como o estádio de desenvolvimento afetaram significativamente a sua viabilidade. Assim, a conservaçâo diminuiu a viabilidade das sementes dos três tipos de frutos coln seis meses de armazenamento, e das sementes de frutos imaturos aos cioze meses. As sementes dos frutos maduros sempre apresentaram os maiores valores e, a dos imaturos, as menores porcentagens de viabilidade.

A baixa viabilidade das sementes pode, talvez, explicar a baixa porcentagem de germinação obtida com sementes de frutos imaturos, após doze meses de armazenamento, mas não nos outros casos, o que sugere a existência de algum mecanismo de dormência em tais sementes. $\mathrm{O}$ alțo nível de dormência ficou evidenciado quando se calculou a porcentagem de sementes dormentes em relação às viáveis. $O$ armazenamento reduziu ligeiramente a dormência de sementes de frutos maduros e meio maduros.

A dormência pode ser devida à necessidade de conōições especiais de fatores, como luz e temperatura, para a germinação, ou à presença de grande quantidade de substâncias inibidoras, como sugerido por RAJASEKARAN et alii (8). Estão em andamento ensaios para esclarecer esses aspectos.

Tanto a conservação da semente como o estádio de desenvolvimento do fruto mostraram efeito significativo sobre o "stand" final das plântulas em casa de vegetação. Assim, enquanto zero e doze meses de armazenamento não causaram diferenças no "stand" final, com seis meses de conservação foram obtidos os maiores valores para os diferentes tipos de sementes usados.

O "stand" final das sementes dos frutos maduros não mostrou valores diferentes daqueles obtidos para as de meio maduros, enquanto as de imaturos apresentaram valores bem inferiores.

$O$ efeito do armazenamento foi significativo sobre a velocidade de emergência das plântulas. Enquanto os estádios de maturação meio maduro e maduro apresentaram maiores velocidades, os dos imaturos mostraram-se sempre inferiores. Notou-se um aumento na velocidade de emergência aos seis meses do fruto imaturo, enquanto ocorreu uma diminuição na do fruto maduro na mesma ocasião.

O peso seco das plântulas provenientes de sementes dẹ frutos imaturos mostrou-se, quando houve significância (zero e doze meses de armazenamento), inferior aos demais. As plântulas dos frutos maduros apresentaram os maiores resultados antes do armazenamento, enquanto as dos meio maduros mostraram os maiores valores dis peso seco aus doze meses de armazenamento. No teste intermediário, foram obtidos os mais baixos valores de peso seco de plântulas, independentemente do estádio de desenvolvimento dos frutos. 
O menor crescimento das plântulas originadas de sementes armazenadas por seis meses pode-se explicar por ter sido o teste realizado durante o inverno, em casa de vegetação, portanto, em condições ambientes naturais. Dessa maneira, houve um alto valor de "stand" de plântulas emergidas, porém estas se desenvolveram mais lentamente. $O$ peso seco das plântulas pode ser usado como parâmetro para avaliar a qualidade e vigor das sementes, mas com restriçōes, pcis foi marcante a irfluência das condições do meio, no caso do cultivar estudado. Testes realizados em épocas do ano com condições ambientes comparáveis (zero e doze meses de armazenamento) mostraram que 0 armazenamento por doze meses é bastante favorável para sementes de frutos meio maduros e praticamente inefetiva para as de frutos maduros ou inaturos.

\section{CONCLUSõES}

O estádio de desenvolvimento do fruto mostrou-se fator importante na viabilidade e germinação das sementes de uva deste cultivar, uma vez que valores mais altos para esses parâmetros foram obtidos com sementes provenientes de frutos maduros: elas apresentaram maior índice de dormência, reduzido, porém, pela simples conservação, da maneira como foi realizada.

Ao considerar o comportamento das sementes em casa de vegetação, no início do armazenamento, as do fruto maduro responderam melhor aos testes, tanto emergindo mais rapidamente como em maior número. No final do armazenamento, no entanto, as sementes dos frutos meio maduros emergiram mais rapidamente, apresentando ainda, as plântulas, pesos superiores às demais. Os resultados indicaram, assim, que a qualidade da semente de uva do cultivar estudado pode-se manter inalterada ou ser melhorada com o armazenamento, principalmente no caso de sementes de frutos maduros e meio maduros.

\section{SUMMARY}

\section{EFFECT OF THE FRUTT DEVELOPMENT STAGE ON THE QUALITY OF 'PATRICIA' GRAPE SEEDS}

During the maturation of the fruits of 'Patricia' grape (Vitis hybrid), three different development stages can be identified based mainly on the fruit color. Seeds in each of these stages were harvested and stored for different periods of time. Seed quality was analysed before and after storage in orcier to detect the maximum capacity of germination and the minimum dormancy level. Seed viability was affected by the fruit maturation stage: high-seed viability was obtained from seeds of mature fruits and low-viability from seeds of immature fruits. During storage a reduction of viability was found for all types of analysed seeds; the ones taken from immature fruits were the most affected. A reduction in the dormancy level occurred in seeds taken from mature fruits during storage. Seeds taken from mature and partially mature fruits emerged sooner and developed into a larger number of plantlets with higher dry weight when compared to those from immature 
fruits independently of being or not stored. In conclusion, in order to obtain high quality grape seeds, with maximun seed viability, it is necessary to wait for the physiological maturity of the fruits before harvesting. This stage can be identified based on the fruit color.

\section{REFERENCIAS BIBLIOGRAFICAS}

1. ARAÛJO, E.F.; MANTOVANI, E.C.; SILVA, A.F. Influência da idade e armazenamento dos frutos na qualidade de sementes de abóbora. In: CONGRESSO BRASILEIRO DE SEMENTES, 2., Recife, 1981. Resumos. p.82.

2. AZEVEDO, J.I.S. de. Effects of delayed harvest upon soybean seed quality. Mississippi, Faculty of Mississippi State University, 1975. 48f. Tese. (Mestrado)

3. BRAsIl. Ministério da Agricultura. Divisão de Sementes e Mudas. Regras para análise de sementes. Brasilia, 1976. 188p.

4. DELOUCHE, J.C.; STILL, T.W.; RASPET, M.; LIENHARD, M. The tetrazolium test for seed viability. Mississippi Agricultural Experiment Station, 1962. 63p. (Technical Bulletin, 51)

5. FATORES que influem na maturação das uvas. Boletim de Agricultura, São Paulo, 37:640-642, 1936.

6. MAGUIRE, J.D. Seed quality and germination. In: KHAN, A.A., ed. The Physiology and Biochemistry of Seed Dormancy and Germination. New York, North-Holland Publ. Co., 1977, 447p.

7. —_ - Speed of germination - aid in selection and evaluation for seedling emergence and vigor. Crop Science, 2:176-177, 1962.

8. RAJASEKARAN, K.; VINE, J.; MULLINS, M.G. Dormancy in somatic embryos and seeds of Vitis: changes in endogenous abscisic acid during embryogeny and germination. Planta, 154:139-144, 1982.

9. RIVES, M. La germination des graines de vigne. I - Essais preliminares. Annales de l'Amélioration des Plantes, 15:79-91, 1965.

10. SANTOS NETO, J.R.A. Patricia e Piratininga, variedades de uvas finas de mesa para climas tropicais. Bragantia, Campinas, 35:CXIX-CXXIII, 1976. (Nota, 24) 